\title{
Short term outcomes after extreme preterm birth in England: comparison of two birth cohorts in 1995 and 2006 (the EPICure studies)
}

\author{
(c) $(1)$ (8)
}

\author{
Kate L Costeloe professor of paediatrics ${ }^{12}$, Enid M Hennessy senior lecturer (statistics) ${ }^{3}$, Sadia \\ Haider research fellow (statistics) ${ }^{3}$, Fiona Stacey research nurse ${ }^{12}$, Neil Marlow professor of neonatal \\ medicine ${ }^{4}$, Elizabeth S Draper professor of perinatal and paediatric epidemiology ${ }^{5}$
}

${ }^{1}$ Centre For Paediatrics, Blizard Institute, Barts and the London School of Medicine and Dentistry, Queen Mary University of London, London, UK; ${ }^{2}$ Homerton University Hospital NHS Foundation Trust, Homerton Row, London ; ${ }^{3}$ Wolfson Institute of Preventive Medicine, Queen Mary University of London, London; ${ }^{4}$ Academic Neonatology, UCL Institute for Women's Health, London; ${ }^{5}$ Department of Health Sciences, University of Leicester, Leicester, UK

\begin{abstract}
Objective To determine survival and neonatal morbidity for babies born between 22 and 26 weeks' gestation in England during 2006, and to evaluate changes in outcome since 1995 for babies born between 22 and 25 weeks' gestation.

Design Prospective national cohort studies.

Setting Maternity and neonatal units in England.

Participants 3133 births between 22 and 26 weeks' gestation in 2006; 666 admissions to neonatal units in 1995 and 1115 in 2006 of babies born between 22 and 25 weeks' gestation.

Main outcome measures Survival to discharge from hospital, pregnancy and delivery outcomes, infant morbidity until discharge.

Results In 2006, survival of live born babies was $2 \%(n=3)$ for those born at 22 weeks' gestation, $19 \%(n=66)$ at 23 weeks, $40 \%(n=178)$ at 24 weeks, 66\% $(n=346)$ at 25 weeks, and $77 \%(n=448)$ at 26 weeks $(P<0.001)$. At discharge from hospital, 68\% $(n=705)$ of survivors had bronchopulmonary dysplasia (receiving supplemental oxygen at 36 weeks postmenstrual age), 13\% ( $n=135)$ had evidence of serious abnormality on cerebral ultrasonography, and 16\% $(n=166)$ had laser treatment for retinopathy of prematurity. For babies born between 22 and 25 weeks' gestation from March to December, the number of admissions for neonatal care increased by 44\%, from 666 in 1995 to 959 in 2006. By 2006 adherence to evidence based practice associated with improved outcome had significantly increased. Survival increased
\end{abstract}

from $40 \%$ to $53 \%(\mathrm{P}<0.001)$ overall and at each week of gestation: by $9.5 \%$ (confidence interval $-0.1 \%$ to $19 \%$ ) at 23 weeks, $12 \%$ (4\% to $20 \%$ ) at 24 weeks, and $16 \%$ (9\% to $23 \%$ ) at 25 weeks. The proportions of babies surviving in 2006 with bronchopulmonary dysplasia, major cerebral scan abnormality, or weight and/or head circumference <-2 SD were similar to those in 1995, but the proportion treated for retinopathy of prematurity had increased from $13 \%$ to $22 \%(P=0.006)$. Predictors of mortality and morbidity were similar in both cohorts.

Conclusion Survival of babies born between 22 and 25 weeks' gestation has increased since 1995 but the pattern of major neonatal morbidity and the proportion of survivors affected are unchanged. These observations reflect an important increase in the number of preterm survivors at risk of later health problems.

\section{Introduction}

Preterm birth is associated with increased rates of neonatal mortality and long term morbidities such as respiratory problems, learning difficulties, cerebral palsy, and behavioural problems, that are highest in the most immature. ${ }^{12}$ This is an important public health issue as rates of preterm birth are rising in many European countries and are particularly high in the United Kingdom. ${ }^{3}$ The first EPICure study collected data for all births in the UK and Ireland before 26 completed weeks' gestation for 10 months in $1995,{ }^{4}$ with detailed information for those babies admitted for intensive care. Outcomes for surviving 
children have been reported to the age of $11 .^{5}$ Since 1995 there has been emphasis on several evidence based interventions to reduce neonatal morbidity. These include increased use of antenatal corticosteroids to promote lung maturation, ${ }^{6}$ strategies to avoid neonatal hypothermia at birth, ${ }^{7}$ increased use of surfactant replacement, ${ }^{8}$ and reduction in the use of postnatal corticosteroids given to prevent bronchopulmonary dysplasia but now thought to be associated with increased cerebral palsy. ${ }^{9}$ From around 2001 neonatal services in England have been organised into clinical "networks" aiming to centralise delivery and intensive care for the most immature infants into tertiary hospitals with greater experience and 24 hour access to neonatal specialist staff. ${ }^{10}$ Regional population based data from the UK show reduced mortality for births before 26 weeks' gestation since $1995 .{ }^{11}$ It is less clear whether there has been change in survival without major morbidity. Reduced severe developmental delay and disability were reported for cohorts from Victoria, Australia, for babies with birth weights below $1000 \mathrm{~g}$ in 1997 and 2005. ${ }^{12}$ In hospital based populations of babies born before 25 weeks' gestation in the United States in 1999-2001 and 2002-04, however, there were no significant changes either in survival or in the prevalence of neurodevelopmental impairment. ${ }^{13}$

Information about the likelihood of survival and childhood impairments is important when discussing clinical decisions with parents and planning services and should be based on the best available data. We have outcomes for births before 26 weeks' gestation in England from the EPICure study of births in 1995. To know whether these outcomes can be extrapolated to babies born in 2006 and more recently requires an understanding of whether the prediction of outcome based on early findings has changed in relation to changes in clinical practice.

EPICure 2 was designed to measure survival and morbidity after extreme preterm birth in 2006 in England and to compare outcomes with outcomes for children in the first EPICure cohort. The first EPICure study recruited births up to and including 25 completed weeks of gestation (that is, up to 25 weeks and 6 days' gestation). In recruitment for EPICure 2 this was extended to include all births at 26 weeks gestational age (that is, 26 weeks and 0 days to 26 weeks and 6 days) both because of a lack of reliable data for babies born at 26 weeks and because babies at this gestation routinely receive active care at birth, forming a useful comparator group. We report outcomes until initial discharge from hospital for babies born in 2006 between 22 and 26 weeks' gestation and compare outcomes for babies born between 22 and 25 weeks in 1995 and 2006.

\section{Methods}

\section{Data collection, completeness, and quality} Births in 2006

Details of all births reported between 22 and 26 weeks' gestation, or more immature but with birth weight over $400 \mathrm{~g}$, were collected prospectively in all 182 maternity hospitals in England. All low risk midwife led centres were contacted early in 2007 to collect details of any births meeting these criteria. To avoid duplication of national data collection we carried out this data collection in collaboration with the Centre for Maternal and Child Health Enquiries. Terminations of pregnancy have been reported separately ${ }^{14}$ and, together with information on births to mothers not usually resident in England, are excluded from this analysis.
We identified contacts in the labour ward and neonatal unit of each hospital to lead the data collection. Monthly logs of eligible births were returned to the EPICure office for monitoring and validation. A member of the study team visited hospitals to collect and complete missing forms and data items. Data were double entered on a bespoke database with intervariable and intravariable range checks to facilitate the highest possible data quality. National data based on gestation at birth were not available at the time of data collection so final checks of completeness were limited to those areas where gestational age based data are routinely collected. The dataset used in 2006 was based on that used in 1995; a complete list of items in the dataset is provided in appendix 1 .

\section{Comparison between births in 1995 and 2006}

In 1995 data enabling confirmation of gestational age were collected only for those babies admitted for intensive care. Our comparisons are therefore between admitted babies born between 22 and 25 weeks' gestation from the 2006 cohort and, to standardise the geographical area, the subset of 666 admitted babies from the 1995 cohort who were born in England.

In 1995, cohort data collection was from 1 March to 31 December. Analyses for the 2006 cohort were run on the whole year and then separately for 1 March to 31 December. There were no large differences; the difference in survival was $0.7 \%$, and the largest difference for any other outcome was $1.3 \%$ for treated retinopathy of prematurity. Data are therefore presented for the whole year for 2006 and the 10 month period in 1995 .

\section{Gestational age}

For both cohorts we based the estimation of gestational age on accepted current best practice. In the 2006 cohort, the earliest ultrasound dating scan was used and, in the absence of any scan, the date of the last menstrual period if it was certain. ${ }^{15}$ In the absence of either scan or certain dates, we based gestation on clinical estimation. In 1995 we based gestation on date of last menstrual period unless a dating ultrasound scan performed before 20 weeks' gestation was discrepant by over 14 days.

Recalculation of gestational age of births in 2006 with the algorithm used in 1995 resulted in a median increase in gestation of 0.2 days and a reduction of total births estimated to be between 22 and 26 weeks' gestation from 3133 to 3088 . As survival and major morbidities were within SD $0.5 \%$ of each other, we used the 2006 estimate throughout.

\section{Principal outcomes Survival}

We measured survival for both cohorts to discharge from hospital. In 2006 survival was calculated based on babies alive at the onset of labour, babies born alive, babies admitted for intensive care, and babies who survived seven days or more. The population alive at the onset of labour was defined by the documented presence of a fetal heart rate either when labour was first diagnosed or caesarean section started or by live birth. In 1995 survival was based on admissions and those surviving seven days or more.

\section{Morbidity}

For babies surviving to discharge from hospital we recorded continued oxygen supplementation at 36 weeks' postmenstrual age (bronchopulmonary dysplasia), findings on cerebral ultrasonography, treated retinopathy of prematurity, surgically treated necrotising enterocolitis, and growth (weight and head 
circumference) using the same definitions as in $1995 .{ }^{4}$ For 2006 births we additionally recorded details of infections with positive results on blood culture and the severity of both

bronchopulmonary dysplasia (moderate disease: no mechanical support and receiving less than $30 \%$ or $\leq 0.1 \mathrm{~L} /$ minute oxygen; severe disease: mechanical support or higher oxygen concentrations, observations made at 36 weeks' postmenstrual age $)^{16}$ and retinopathy of prematurity (stages I-V). ${ }^{17}$ Findings on cerebral ultrasonography are presented for the last scan data that were available.

Survival without major morbidity was defined as survival to discharge without severe changes on cerebral ultrasonography (no ventrigulomegaly, echodense haemorrhagic parenchymal infarction, porencephaly, or periventricular leucomalacia ) on any scan, "severe" bronchopulmonary dysplasia, ${ }^{16}$ retinopathy of prematurity $\geq$ stage 3 , or laparotomy for necrotising enterocolitis.

\section{Determinants of death and major morbidity}

We developed prediction models using those items known within 24 hours of birth that had been used in the analysis of the 1995 cohort. ${ }^{4}$ These models were used to investigate any changes between 1995 and 2006 (cohort effect) in the survival of admitted babies and major morbidity (major cerebral injury on ultrasonography, bronchopulmonary dysplasia, continued use of supplementary oxygen at 40 weeks' postmenstrual age, and treated retinopathy of prematurity).

\section{Statistical analysis}

Outcomes were summarised as proportions, means, and medians, as appropriate. We used logistic, linear, and centile regressions, respectively, to investigate the effect of gestational age (in decimal weeks). For each week of gestation, we report exact $95 \%$ binomial confidence intervals of percentages and percentage differences.

In the prediction models we used interaction terms to test whether the associations of variables with outcomes were different in the two cohorts. Any unexplained differences between 1995 and 2006 were tested using "cohort" as a variable, thus cohort is included in all the models. We used multivariable logistic regression with a manual forward stepwise procedure with replacement.

Stata statistical software (release 10.1; College Station, TX) was used for all analyses and Kaplan-Meier survival curves. No allowance was made for multiple tests, and significance was set at $\mathrm{P} \leq 0.05$.

\section{Results \\ 2006 cohort}

A total of 3378 births were reported to the study centre. Consideration of ultrasound scans and menstrual dates confirmed the gestation of 236 to be outside the range 22-26 weeks. Data for nine other births were excluded, two at parental request and seven, all of whom were either stillborn or died in the delivery room, because there was inadequate information to determine gestational age. The 3133 births in which gestation was confirmed as between 22 and 26 weeks form the basis of our analysis (table $1 \Downarrow$ ). One baby was stillborn in a midwife led maternity unit, 34 (19 live births) were born at home, and 27 (19 live births) were born elsewhere outside the hospital.

For 3039 (97\%) fetuses, gestation was confirmed by ultrasonography; the median gestation at the first dating scan was 12 weeks and 4 days (interquartile range 11 weeks 1 day-14 weeks 5 days). Of the 94 remaining, menstrual dates were certain for 16 and the gestational age for 78 was agreed by clinical assessment; in three of these the paediatricians revised the obstetric assessment. Validation of the data for the East Midlands and Yorkshire regions with data from the neonatal survey ${ }^{18}$ indicated a match for over $98 \%$ cases before the final completion of the cohort.

Of the total of 3133 babies, the proportion known to be alive at the onset of labour $(\mathrm{n}=2326)$ ranged from $57 \%(\mathrm{n}=272)$ at 22 weeks' gestation to $81 \%(n=594)$ at 26 weeks, $(\mathrm{P}<0.001$ table $1 \Downarrow)$. Of 1099 stillbirths, 715 were antepartum and 292 were intrapartum; the time of fetal death of the 92 other was unknown.

\section{Status at delivery and care at birth}

Of the 2326 babies known to be alive at the onset of labour, 2034 were born alive; the proportion ranged from $56 \%(n=152)$ at 22 weeks' gestation to $98 \%(\mathrm{n}=580)$ at 26 weeks $(\mathrm{P}<0.001$; table $1 \Downarrow)$. The proportion of liveborn babies for whom active stabilisation was withheld at birth decreased with increasing gestation: $73 \%(111 / 152)$ at 22 weeks, $16 \%(55 / 338)$ at 23 weeks, and $<2 \%(23 / 1535)$ at $24-26$ weeks (table $1 \Downarrow)$. Of the 78 babies born after 23 completed weeks for whom stabilisation was withheld, six ( $8 \%$ ) had a potentially lethal malformation known before, or apparent at, birth. Three babies were admitted to a neonatal unit for palliative care; all died within 24 hours of admission.

Of the liveborn babies offered stabilisation, 95\% (1751/1838) had endotracheal intubation and 72\% (1303/1810) were treated with surfactant in the delivery room. Delivery room surfactant use increased linearly with gestational age from $46 \%(19 / 41)$ at 22 weeks' gestation through $66 \%(183 / 276)$ at 23 weeks to $77 \%(435 / 565)$ at 26 weeks $(\mathrm{P}<0.001)$. Occlusive wrapping to prevent hypothermia was applied at birth to $62 \%(1176 / 1891)$ of liveborn babies, increasing from $16 \%$ (24/148) at 22 weeks' gestation through 53\% (169/321) at 23 weeks to $72 \%(376 / 525)$ at 26 weeks $(\mathrm{P}<0.001)$. The frequency of hypothermia at admission reduced with increasing gestational age (table $1 \Downarrow$ ), even after adjustment for the use of occlusive wrapping: odds ratio 0.54 per week (confidence interval 0.46 to 0.62 ). Full details of birth weight for liveborn babies and those admitted for neonatal intensive care by gestation, sex, and plurality are provided in appendices 2 and 3.

\section{Survival}

Survival to 28 days and to discharge from hospital rose with increasing gestational age (table $1 \Downarrow$ ). For the lower gestational ages, because death was more common in the delivery room, there are important differences in survival to 28 days and to discharge from hospital when it is expressed using admissions rather than live births as the denominator. In 2006, babies died on average 6.7 days (confidence interval 4 to 9 days) later per additional week of gestational age (fig $1 \Downarrow$ ). Median length of stay in hospital for all survivors was 102 days (interquartile range 86-113 days), decreasing from 124 days at 22 weeks' gestation to 134 days at 23 weeks and 91 days at 26 weeks $(\mathrm{P}<0.001$; table $1 \Downarrow)$.

\section{Interventions}

Antenatal steroids-Of liveborn babies, $76 \%$ had been exposed to antenatal steroids, increasing from $14 \%$ at 22 weeks' gestation to $58 \%$ at 23 weeks, $84 \%$ at 24 weeks, $88 \%$ at 25 weeks, and $86 \%$ at 26 weeks; $46 \%$ overall received a complete course. Between 24 and 26 weeks' gestation, $55 \%$ of babies admitted to neonatal intensive care received a complete course of 
antenatal steroids compared with $30 \%$ at 23 weeks' gestation; table $1 \Downarrow)$.

Surfactant - Of the 1281 admitted babies known to have been treated with surfactant replacement in the delivery room, 931 $(72 \%)$ received at least one further dose after admission. A further 361 of the 377 babies who did not receive surfactant in the delivery room were treated after admission, so that $99 \%$ of babies admitted received some surfactant treatment.

Nutrition-All but one of the surviving babies received parenteral nutrition in the days after birth; $96 \%$ received maternal breast milk at some time and $42 \%$ continued to receive some breast milk at discharge from hospital. Rates of breast feeding did not vary significantly with gestational age.

Postnatal steroids - Steroids were used to aid the weaning of babies from ventilation in 16\% (161/1039) of survivors $(21 \%$ (122/593) born before 26 weeks of gestation), starting at a median age of 29 days (interquartile range 20-45) and given for a median of 12 days (8-20). No baby was started on steroids for this indication within the first seven days. Of the surviving treated babies, 150 (94\%) were prescribed dexamethasone: median starting dose $0.2 \mathrm{mg} / \mathrm{kg} /$ day (interquartile range 0.15-0.5). Steroid use was more common at lower gestational ages $(\mathrm{P}<0.001)$; the timing of commencement, duration of use, and starting dose did not change with gestation.

\section{Major morbidity in survivors to discharge}

Respiratory morbidity - Of the 761 babies who were still alive at 36 weeks postmenstrual age and still receiving supplementary oxygen, $293(39 \%)$ were classified as having moderate and 468 $(61 \%)$ as severe bronchopulmonary dysplasia; three $(1 \%)$ of the moderate group and $44(9 \%)$ of the severe group died without leaving hospital. Of the survivors, $36 \%$ of the moderate and $62 \%$ of the severe group were discharged home with supplementary oxygen.

Findings on cerebral ultrasonography-Unlike the other major morbidities, the proportion of surviving babies who had a severe abnormality reported on cerebral ultrasonography $(13 \%, 95 \%$ confidence interval $11 \%$ to $15 \%$ ) was not related to gestational age (table $2 \Downarrow$ ).

Treated retinopathy of prematurity — Of the 166 surviving babies who had laser treatment for retinopathy, $150(90 \%)$ had stage 3 to stage 5 disease, and 162 (98\%) had both eyes treated.

Laparotomy for necrotising enterocolitis-Laparotomies for necrotising enterocolitis were performed in 79 (8\%) surviving babies. Details were not collected for episodes of necrotising enterocolitis treated medically.

Overall 423 (41\%) of survivors to discharge from hospital had no reported major morbidity.

\section{Comparison of outcomes for children born in 1995 and 2006 between 22 and 25 weeks' gestation}

\section{Characteristics of admitted babies}

Table $3 \Downarrow$ gives comparative characteristics for the two cohorts. The number of admissions for neonatal care of babies born from March to December with gestational age between 22 and 25 weeks increased by 44\% from 666 in 1995 to 959 in 2006. The numbers of admissions varied by ethnic group, being higher for babies born to Afro-Caribbean women and those from the Indian subcontinent, so that the proportion of babies born to white women decreased significantly (table 3 ).
From 1995 to 2006, the proportions of admitted babies born after exposure to tocolytics and antenatal steroid increased, as did reports of birth after a clinical diagnosis of chorioamnionitis, while the prevalence of antepartum haemorrhage decreased. In contrast, the proportion of singleton births, boys, and births by caesarean section, both before and after the onset of labour, and the distribution of birth weight by gestation were similar between the two cohorts. Improved early condition of babies born in 2006 was reflected in more having a heart rate over 100 beats per minute by five minutes, many fewer having admission temperatures below $35^{\circ} \mathrm{C}$, and lower median and mean clinical risk index for babies (CRIB I) scores $^{19}$ (table 3). $\Downarrow$

\section{Changes in survival}

Survival to discharge from hospital for all admitted babies born between 22 and 25 weeks' gestation increased from $40 \%$ (266/666) in 1995 to $53 \%(593 / 1115)$ in 2006, an increase of $13 \%$ ( $95 \%$ confidence interval $8 \%$ to $18 \%$ ). Survival increased at each week of gestation: by $9.5 \%(-0.1 \%$ to $19 \%)$ at 23 weeks, $12 \%(4 \%$ to $20 \%)$ at 24 weeks, and $16 \%(9 \%$ to $23 \%)$ at 25 weeks. This improved survival reflects the greater numbers of babies surviving the first week after birth; the probability of survival for babies at each week of gestation for those who survived the first seven days was no different between the two cohorts (fig 1). $\Downarrow$

The median age at death in 2006 was 7 days, compared with 2 days in 1995; this is reflected in changes in the reported principal cause of death in the babies who died: fewer deaths in 2006 were attributed to very early respiratory failure (pulmonary insufficiency) and more to later complications of prematurity: infection and necrotising enterocolitis (table $4 \Downarrow$ ). Expressed as a proportion of those alive on the seventh day, in 2006 death from infection was $4 \%$ higher $(95 \%$ confidence interval $0.5 \%$ to $7 \%$ ) and death from necrotising enterocolitis was $4 \%$ (2\% to $6 \%$ ) higher.

\section{Hospital stay}

The median length of stay in hospital for all survivors decreased from 119 to 111 days ( -8 days, $95 \%$ confidence interval -15 to -1 day); there was no change at 23 weeks' gestation, a decrease of 16 days at 24 weeks, and a decrease of 10 days at 25 weeks

\section{Changes in neonatal morbidities}

The prevalence of major morbidities in survivors in 2006 was strikingly similar to 1995, with no differences in the proportions with bronchopulmonary dysplasia, major cerebral injury (ventriculomegaly, haemorrhagic parenchymal infarcts, or parenchymal cysts) on the last available ultrasound scan (fig $2 \Downarrow$ ), or of the decrease in the SD score for birth weight and occipitofrontal circumference between birth and the expected date of delivery (fig $3 \Downarrow$ ). In contrast, the proportion of babies discharged while still receiving supplementary oxygen $(41 \%)$ had increased by $7 \%$ (95\% confidence interval $-0.2 \%$ to $14 \%$ ) and the number who had laser treatment for retinopathy of prematurity increased overall by $8 \%$ (3\% to $13 \%$; fig 2 ), this difference was unaffected by gestational age.

\section{Determinants of outcomes}

The univariable associations were strikingly similar between the two cohorts (see appendix 3). The most notable changes were, firstly, the weakening of the relation between hypothermia and death and, secondly, the lack of association between transfer after birth with either severe abnormality on cerebral 
ultrasonography or prolonged requirement for oxygen. This occurred despite an increased proportion of babies being transferred within 24 hours of birth (table $3 \Downarrow$ ). Antepartum haemorrhage and CRIB I score showed different associations in the two cohorts (see appendix 3). In the multivariable prediction models, the perinatal variables in table $5 \Downarrow$ were significantly associated with one or more adverse outcome in the combined cohorts and, with the exception of CRIB I score, similarly when we considered each cohort separately. The association between CRIB I score and death before discharge was different between the two cohorts (odds ratio 0.93, 95\% confidence interval 0.97 to 0.99 ).

Two variables, neither of which was predictive with any outcome in the combined cohorts, had significant associations in one cohort when we considered them independently: transfer within 24 hours of birth with severe abnormality on cerebral ultrasonography in 1995 and antepartum haemorrhage with survival in 2006. CRIB I score was associated with treated retinopathy of prematurity in 2006 (odds ratio $1.10,95 \%$ confidence interval 1.02 to 1.18 ) but not in 1995 .

The effect of cohort (table $5 \Downarrow$ ) describes the risk of adverse outcomes after adjustment for the condition of the baby in the first 24 hours. For each outcome considered the risk was greater in 2006 but only significantly so for treated retinopathy of prematurity, suggesting that the improvement observed in survival relates to improved early condition rather than to any later factors.

\section{Discussion}

This study tracking outcomes of extremely preterm births in a large geographically defined population showed improved survival in 2006 compared with 1995 and several markers of improved clinical practice. Despite this, the pattern of major short term morbidities and the associations between early clinical items and adverse outcomes were similar.

EPICure 2 represents the first opportunity to report the changes over time for perinatal and neonatal outcomes of a whole country's extremely preterm births. Planning support for survivors of preterm birth requires an understanding of their needs through childhood and adolescence into adult life. The survivors from the first EPICure study, who were born in 1995, form the largest reported population based cohort of extremely preterm survivors; their follow-up has documented a range of problems associated with preterm birth with lifelong implications. ${ }^{50-23}$ EPICure 2 provides not only more recent information but also the opportunity to study any changes in the pattern of morbidity in survivors so that we can better understand whether the longer term outcomes of the 1995 EPICure cohort are valid for babies born more recently.

We decided to limit the study to England for practical reasons in anticipation of around 3500 births and 1650 admissions; in 1995 there had been no differences in major morbidities between England and the other UK countries and Ireland. We included births at a gestational age of 26 weeks in 2006 because of lack of population based data for those babies and because such babies are routinely offered intensive care, thus providing a useful comparator group. We found no stepwise differences in outcome between 25 and 26 weeks, rather a continuum of morbidity-free survival across the gestation range.

The rates of preterm birth in the UK, while lower than in the US, seem to be higher than in other European countries. ${ }^{3}$ The significant increase in admissions before 26 weeks' gestation between the two cohorts needs to be better understood. In the East Midlands Region of the UK, there was no increase in extremely preterm admissions over the same time period, ${ }^{11}$ suggesting that there might be geographical variation. The change in the ethnicity profile between the two cohorts is difficult to interpret and takes no account of new waves of immigration over this period, which covers the incorporation of Eastern European countries in to the European Union with associated economic migration into the UK; details of the country of birth of the mother were not collected.

Overall survival in 2006 has increased since 1995, although not significantly for births before 24 weeks' gestation. This change results from improved survival to the end of the first week, with little difference thereafter. There is evidence of increased adherence to evidence based practice in 2006, which could account for improved condition of babies shortly after birth and explain improved outcomes in the first week. The prevalence of major morbidities in survivors, however, seems not to have improved either when evaluated alone or after adjustment for status within 24 hours of birth.

The apparent absence of improved survival in 2006 after the first week is clinically important. Increased survival in the first week could result in a population entering the second week at higher risk of complications because of the survival of babies who would previously have died. This is supported by increased reporting of sepsis confirmed by blood culture and necrotising enterocolitis as the primary cause of death in those surviving the first week. Set against this, the lack of improvement in somatic or head growth over the admission to neonatal intensive care and the high rates of nosocomial infection reported in 2006 emphasise the urgency of developing safe and effective strategies to improve early growth and prevent late infective complications if further improvement in outcome is to be achieved. In this context three aspects of care after admission are noteworthy.

Firstly, from around 2003 the historical dispersed pattern of provision of neonatal intensive care in England was reorganised into networks with designated tertiary neonatal intensive care units and improved access to dedicated postnatal transfer services. ${ }^{24}$ Despite encouragement of antenatal maternal transfer, $42 \%$ of live births at less than 26 weeks' gestation in 2006 took place outside the tertiary centres, and the proportion of babies transferred within 24 hours of birth for intensive care had increased significantly since 1995 (table $3 \Downarrow$ ). Perhaps because of better trained and equipped transport teams, however, babies transferred in 2006 did not show the adverse outcomes associated with transfer seen in 1995 (table 5). $\Downarrow$

Secondly, in 2006 the use of postnatal steroid in survivors declined from $71 \%$ to $21 \%$ and median length of treatment declined from 21 to 12 days. In the 1995 cohort this was associated in a dose dependent manner with severe motor impairment at 30 months. ${ }^{25}$ Furthermore, it is likely that the median starting dose $(0.2 \mathrm{mg} / \mathrm{kg} /$ day $)$ is lower and the overall exposure to steroid greatly reduced.

Thirdly, the use of any maternal breast milk in survivors, associated in 1995 with improved psychomotor developmental index at 30 months, ${ }^{22}$ increased in 2006 for those born before 26 weeks from $86 \%$ to $96 \%$. In $2006,43 \%$ of all surviving babies were receiving breast milk at discharge.

The emerging picture would seem to favour improved outcomes and yet the pattern of major neonatal morbidities (fig $2 \Downarrow$ ) is strikingly similar to that in 1995. The observed increase in treated retinopathy of prematurity might represent a change of practice, with improved access to retinal screening and ophthalmologists recommending treatment at earlier stages of disease. Likewise the observed increase in the number of babies 
being discharged while still receiving supplementary oxygen, which is associated with earlier discharge from hospital, is likely to represent improved access to community nursing support. Neither explanation can be confirmed. Some of the variation in the strength of associations apparent in the analyses is probably because of the increased size of the 2006 cohort. A small change in reporting in 2006 to distinguish antepartum haemorrhage from placental abruption could explain the differential effect in the two cohorts, and different clinical indications for treatment of retinopathy could account for the altered association with CRIB I score. The most striking outcome of these analyses, however, is the consistency between the two cohorts and the lack of evidence, after adjustment for the condition of the baby shortly after birth, of improved survival or changed proportion of survivors with either bronchopulmonary dysplasia or severe abnormality on cerebral ultrasonography.

Clinical condition around the time of preterm birth is increasingly understood to be a critical determinant of later outcome. ${ }^{2627} 28$ The consistency of the predictive models for short term outcomes across the two EPICure cohorts suggests that early predictors of outcomes in the 1995 cohort $^{25}$ will remain predictive of longer term outcomes in the 2006 cohort.

In the context of other population based studies, direct international comparisons are complicated by a lack of standardised data collection. In a review including population based reports of live births before 26 weeks' gestation between 1995 and $2000,{ }^{2}$ survival for the 1995 EPICure cohort seemed to be the lowest, with the highest being from the northern part of Sweden. This was attributed to a positive approach on the part of both obstetricians and neonatologists with centralisation of specialist services and high rates of caesarean section and provision of neonatal intensive care. ${ }^{29}$ Subsequently the EXPRESS study reported outcomes for 1011 births between 22 and 26 weeks' gestation from the whole of Sweden for 2004-07, with high survival at 12 months of age (70\% of live births overall, $53 \%$ born at 23 weeks, and $85 \%$ born at 26 weeks). ${ }^{30}$ We derived a definition of survival without major morbidity for the EPICure 2006 cohort (table $2 \Downarrow$ ) that is close to that used in the EXPRESS study. Three of the babies who survived to discharge, all of whom had major morbidity, died before their first birthday. Despite such big differences in survival between the two studies, the proportions of survivors without major morbidity at one year in the EPICure $2(41 \%, 95 \%$ confidence interval $38 \%$ to $44 \%)$ and EXPRESS cohorts $(45 \%, 41 \%$ to $50 \%$ ) are similar.

\section{Strengths of this study}

The main strengths of this study are the size of the cohort, representing a complete national cohort and recruited with high ascertainment, and the quality of the data. All the babies were born over a short time span, and our findings are relevant to current practice. We received high cooperation from clinical staff and are confident that ascertainment is virtually $100 \%$. As in the first study, all outlying and ambiguous data were checked with contributors and further checked and corrected if necessary at analysis. All data were double entered to check validity, in contrast with the first study in which only $10 \%$ of data were double entered.

We constrained our definitions of variables to match those of the original study, and it was therefore possible to track changes over time in clinical outcomes for this important vulnerable population. Additionally, in 2006 enhanced data were collected for all births, including stillbirths, so that outcomes could reliably be expressed with relevant denominators including total and live births and that further analyses could be undertaken to understand determinants of condition at birth.

\section{Limitations of the study}

In 2006 it was not possible to collect these data electronically because of patchy access to suitable computer facilities in maternity and neonatal units, and yet all data items would be expected to be available in the clinical record. The data collection imposed a huge volume of additional work for clinical staff and the checking of missing and ambiguous data is time consuming and causes delay in closing of databases and analysis. Since 2006, standardised electronic data have been collected in English neonatal units, and this is now almost universal with developing systems for the centralisation of data for audit and research purposes. ${ }^{31}$ In future, electronic data captured for routine clinical purposes should be of sufficient quality to provide the basis for such studies, making them easier, less expensive, and with results more readily available.

Gestational age is the most important predictor of survival for the preterm baby and is favoured over birth weight as the principal criterion for defining preterm cohorts. Nonetheless, the determination of gestation remains imprecise. Best practice for the estimate of gestation has changed over time; consequently a different algorithm was used for each cohort. This produced only minor differences in survival and major morbidities, so for this reason and for ease of comparison with other contemporary cohorts, we have presented outcomes for the 2006 cohort with the contemporary algorithm.

\section{Recent changes in neonatal practice}

It is important to consider whether changes since 2006 might have affected our findings. We are not aware of any reliable data supporting further centralisation of delivery of babies born before 27 weeks' gestation in England or further improvement in the condition of babies at birth. Interest continues in minimising overexpansion of the lungs at birth and exposure to unnecessarily high concentrations of oxygen. ${ }^{32}$ Randomised trials have confirmed that the early application of nasal continuous positive airway pressure (CPAP) to babies who establish breathing spontaneously ${ }^{33} 34$ and, more recently, the use of nebulised surfactant replacement ${ }^{35}$ can reduce the number of babies who require endotracheal intubation. The role of probiotics to prevent sepsis, necrotising enterocolitis, and death remains controversial. ${ }^{36}$ Few babies born between 22 and 26 weeks' gestation are included in the published trials of any of these interventions, and longer term outcomes have not been reported. Other factors that might in time feed through to better outcomes include collaborative quality improvement initiatives, ${ }^{37}$ which through the introduction of standardised "care bundles," have been shown to be effective in reducing catheter related sepsis in newborn infants. ${ }^{38}$ Given the lack of change in the pattern of morbidity in surviving extremely preterm babies between 1995 and 2006, a period when evidence based practice was increasing, it seems unlikely that it has changed since 2006.

\section{Summary}

Our findings support the validity of using longer term outcome data from the 1995 EPICure cohort when considering the prognosis for contemporary babies. Though the pattern of major short term morbidities and the associations of early clinical items with adverse outcomes were similar, there has been a $44 \%$ increase in the numbers of extremely immature babies being admitted to our neonatal intensive care units. Increased admissions, increased survival, and unchanged rates of major 
adverse outcomes suggest that the while the total number of children surviving extremely preterm birth free from impairments will rise, so will the number with long term health problems. This represents an important increase in workload for health, educational, and social services.

We are grateful for the cooperation of the Confidential Enquiry into Maternal and Child Health (CEMACH); for the help of Kerry Montoute, Elizabeth Rushmer, Rachel Lee, and Catherine Kelly in the EPICure 2 office at Homerton University Hospital NHS Foundation Trust; for database development by Martin Perkins and data entry by Helen Holden at the University of Leicester; and particularly for the staff of contributing hospitals listed in appendix 5 . The perinatal component of the EPICure studies was sponsored by Queen Mary, University of London. NM receives part funding from the Department of Health's NIHR Biomedical Research Centre's funding scheme at UCLH/UCL.

Independent members of EPICure 2 perinatal committee

Zarko Alfirevic, Alan Gibson, Shona Golightly, Alison Miller, Michael Webb, Andrew Wilkinson.

Independent members of EPICure studies steering committee

Peter Brocklehurst (chairman), Jane Abbott, Andrew Bush, Richard Cooke, Noreen Maconochie, Alison Matthews, David Matthews, Richard Morton, Maggie Redshaw, David Taylor, Nigel Turner, Diane Turner, Patrick Walsh.

Contributors: KLC and NM developed the hypothesis; KLC and ESD supervised the data collection; FS collected data for both EPICure cohorts and led the validation of EPICure 2 data; KLC, EMH, and SH analysed the data. KLC wrote the first draft and coordinated the production of the manuscript and is guarantor. All authors were involved in the interpretation of the data and writing the report; all have approved the final version.

Funding: The study was funded by the Medical Research Council (G0401525). The funders had no role in study design, data collection, data analysis, data interpretation, or writing of the report.

Competing interests: All authors have completed the ICMJE uniform disclosure form at www.icmje.org/coi_disclosure.pdf (available on request from the corresponding author) and declare: no support from any organisation for the submitted work; no financial relationships with any organisations that might have an interest in the submitted work in the previous three years and no other relationships or activities that could appear to have influenced the submitted work.

Ethical approval: The study was approved by the East London Research Committee (ref No 05/Q0605/107). Further approval was obtained (PIAG 3-07(f)/2005) to collect data without explicit consent. For surviving infants we sought consent to use the data, maintain contact with the family, and to arrange for long term developmental assessment.

Data sharing: The EPICure studies are subject to a data sharing policy that may be downloaded from www.epicure.ac.uk.

Marlow N. Neurocognitive outcome after very preterm birth. Arch Dis Child Fetal Neonatal Ed 2004:89:F224-8.

2 Saigal S, Doyle LW. An overview of mortality and sequelae of preterm birth from infancy to adulthood. Lancet 2008;371:261-9.

3 Field D, Draper ES, Fenton A, Papiernik E, Zeitlin J, Blondel B, et al. Rates of very preterm birth in Europe and neonatal mortality rates. Arch Dis Child Fetal Neonatal Ed 2009;94:F253-6.

4 Costeloe K, Hennessy E, Gibson AT, Marlow N, Wilkinson AR. The EPICure study: outcomes to discharge from hospital for infants born at the threshold of viability. Pediatrics 2000;106:659-71.

5 Johnson S, Fawke J, Hennessy E, Rowell V, Thomas S, Wolke D, et al. Neurodevelopmental disability through 11 years of age in children born before 26 weeks of gestation. Pediatrics 2009;124:e249-57.

6 Roberts D, Dalziel S. Antenatal corticosteroids for accelerating fetal lung maturation for women at risk of preterm birth. Cochrane Database Syst Rev 2006;4:CD00454.

7 McCall EM, Alderdice F, Halliday HL, Jenkins JG, Vohra S. Interventions to prevent hypothermia at birth in preterm and/or low birthweight infants. Cochrane Database Syst Rev 2010;3:CD004210.
8 Suresh GK, Soll RF. Overview of surfactant replacement trials. J Perinatology 2005;25:S40-4.

9 AAP Committee on Fetus and Newborn. Postnatal corticosteroids to prevent or treat bronchopulmonary dysplasia. Pediatrics 2010;126:800-8

10 Marlow N, Gill AB. Establishing neonatal networks: the reality. Arch Dis Child Fetal Neonatal Ed 2007;92:F137-42.

11 Field DJ, Dorling JS, Manktelow BN, Draper ES. Survival of extremely premature babies in a geographically defined population: prospective cohort study of 1994-9 compared with 2000-5. BMJ 2008;336:1221-3.

12 Doyle LW, Roberts G, Anderson PJ; the Victorian Infant Collaborative Study Group. Changing long-term outcomes for infants 500-999g birthweight in Victoria, 1979-2005. Arch Dis Child Fetal Neonatal Ed 2011;96:F443-7.

13 Hintz SR, Kendrick DE, Wilson-Costello DE, Das A, Bell EF, Vohr BR, et al. Early-childhood neurodevelopmental outcomes are not improving for infants born at $<25$ weeks' gestational age. Pediatrics 2011;127:62-70

14 Draper ES, Alfirevic Z, Stacey F, Hennessy E, Costeloe K, for the EPICure Study Group. An investigation into the reporting and management of late terminations of pregnancy (22+0 to 26+6 weeks gestation) within NHS Hospitals in England in 2006: the EPICure 2 preterm cohort study. BJOG 2012;119:710-5.

15 Antenatal care: routine care for the healthy pregnant woman. NICE guideline. RCOG Press, 2008. www.rcog.org.uk.

16 Jobe AH, Bancalari E. Bronchopulmonary dysplasia. Am J Respir Crit Care Med 2001;163:1723-9.

17 International Committee for the Classification of Retinopathy of Prematurity. The international classification of retinopathy of prematurity revisited. Arch Ophthalmol 2005;123:991-9.

18 Neonatal survey report 2006. Department of Health Sciences, University of Leicester.

19 International Neonatal Network. The CRIB (clinical risk index for babies) score: a tool for assessing initial neonatal risk and comparing performance of neonatal intensive care units. Lancet 1993;342:193-8.

20 Johnson S, Hollis C, Kochhar P, Hennessy EM, Wolke D, Marlow N. Autism spectrum disorders in extremely preterm children. $J$ Pediatrics 2010;156:525-31.

21 Fawke J, Lum S, Kirkby J, Hennessy EM, Marlow N, Rowell V, et al. Lung function and respiratory symptoms at 11 years in children born extremely preterm. Am J Respir Crit Care Med 2010;182:237-45.

22 McEniery CM, Bolton CE, Fawke J, Hennessy EM, Stocks J, Wilkinson JR, et al. Cardiovascular consequences of extreme prematurity: the EPICure study. $J$ Hypertens 2011;29:1367-73.

23 Walker SM, Franck LS, Fitzgerald M, Myles J, Stocks J, Marlow N. Long-term impact of neonatal intensive care and surgery on somatosensory perception in children born extremely preterm. Pain 2009;141:79-87

24 Department of Health Expert Working Group. Neonatal intensive care services: report of the consultation. Department of Health, 2003.

25 Wood NS, Costeloe K, Gibson AT, Hennessy E, Marlow N, Wilkinson AR for the EPICure study group. The EPICure study: associations and antecedents of neurological and developmental disability at 30 months of age following extremely preterm birth. Arch Dis Child Fetal Neonatal Ed 2005;90:134-40.

26 Johnson S, Wolke D, Hennessy E, Marlow N. Educational outcomes in extremely preterm children: neurophysychological correlates and predictors of attainment. Dev Neuropsycho 2011;36:74-95.

27 Messerschmidt A, Olishar M, Birnbachedr R, Sauer A, Weber M, Pushniq D, et al. Is it possible to make a reliable prognosis within the first hour of life for very low birthweight infants delivered after preterm rupture of membranes? Neonatology 2011;99:146.

28 Beaino G, Khoshnood B, Kaminski M, Pierrat V, Marret S, Matis J, et al, EPIPAGE Study Group. Predictors of cerebral palsy in very preterm infants: the EPIPAGE prospective population-based cohort study. Dev Med Child Neurol 2010;52:e119-25.

29 Hakansson S, Faroogi A, Holmgren PA, Serenius F, Hogberg U. Proactive management promotes outcome in extremely preterm infants: a population based comparison of two perinatal management strategies. Pediatrics 2004;114:58-64.

30 EXPRESS Group. One-year survival of extremely preterm infants after active perinatal care in Sweden. JAMA 2009;301:2225-33.

31 Spencer A, Modi N. National neonatal data to support specialist care and improve infant outcomes. Arch Dis Child Fetal Neonatal Ed 2012 Jan 3, epub ahead of print

32 Dawson JA, Vento M, Finer NN, Rich W, Saugstad OD, Morley CM, et al. Managing oxygen therapy during delivery room stabilization of preterm infants. $J$ Pediatrics 2012;160:158-61.

33 Morley CJ, Davis PG, Doyle LW, Brion LP, Hascoet J-M, Carlin JB for the CoIN Trial Investigators. Nasal CPAP or intubation at birth for very preterm infants. N Engl J Med 2008;358:700-8.

34 SUPPORT Study Group. Early CPAP versus surfactant in extremely preterm infants. N Engl J Med 2010;362:1970-9.

35 Gopel W, Kribs A, Ziegler A, Laux R, Hoehn T, Wieg C, et al. Avoidance of mechanical ventilation by surfactant treatment of spontaneously breathing preterm infants (AMV): an open-label, randomised, controlled trial. Lancet 2011;378:1627-34.

36 Indrio $\mathrm{F}$, Neu J. The intestinal microbiome of infants and the use of probiotics. Curr Opin Pediatr 2011;23:145-50.

37 Horbar JD. The Vermont Oxford Network: evidence-based quality improvement for neonatology. Pediatrics 1999;103:350.

38 Schulman J, Stricof R, Stevens TP, Horgan M, Gase K, Holzman IR, et al. Statewide NICU central-line-associated bloodstream infection rates decline after bundles and checklists. Pediatrics 2011;127:436-44.

Accepted: 09 November 2012

\section{Cite this as: BMJ 2012;345:e7976}

This is an open-access article distributed under the terms of the Creative Commons Attribution Non-commercial License, which permits use, distribution, and reproduction in any medium, provided the original work is properly cited, the use is non commercial and is otherwise in compliance with the license. See: http://creativecommons.org/licenses/by$\mathrm{nc} / 2.0 /$ and http://creativecommons.org/licenses/by-nc/2.0/legalcode. 


\section{What is already known on this topic}

Mortality and morbidity are high after extremely preterm birth

Children who survive preterm birth experience a range of problems requiring additional help from health, educational, and social services and with lifelong implications

\section{What this study adds}

Between 1995 and 2006, the number of admissions to neonatal intensive care units of babies born between 22 and 25 weeks' gestation increased by $44 \%$

Survival of babies born between 22 and 25 weeks' gestation has increased, but the proportion of survivors with major neonatal morbidity is unchanged

These changes suggest that the total number of children in the community with lifelong health problems attributable to extremely preterm birth will rise

\section{Tables}

Table 1 | Perinatal characteristics of births between 22 and 26 weeks' gestation in 2006 and survival to discharge from hospital. Figures are numbers (percentages, as shown), unless stated otherwise

\begin{tabular}{|c|c|c|c|c|c|c|c|}
\hline & \multicolumn{6}{|c|}{ Gestational age (weeks) } & \multirow[b]{2}{*}{ P value* } \\
\hline & 22 & 23 & 24 & 25 & 26 & $22-26$ & \\
\hline \multicolumn{8}{|l|}{ Births (including all stillbirths) } \\
\hline Total & 478 & 594 & 636 & 692 & 733 & 3133 & - \\
\hline Antepartum stillbirths & 158 & 153 & 133 & 140 & 131 & 715 & - \\
\hline $\begin{array}{l}\text { Alive at onset of labourt (\% } \\
\text { total births) }\end{array}$ & $272(57)$ & $416(70)$ & $494(78)$ & $550(80)$ & $594(81)$ & $2326(74)$ & - \\
\hline Intrapartum stillbirths & 120 & 77 & 52 & 29 & 14 & 292 & - \\
\hline $\begin{array}{l}\text { Time of intrauterine death } \\
\text { unknown }\end{array}$ & 48 & 25 & 9 & 2 & 8 & 92 & - \\
\hline \multicolumn{8}{|l|}{ Live births } \\
\hline $\begin{array}{l}\text { Total (\% alive at onset of } \\
\text { labour) }\end{array}$ & $152(56)$ & $339(81)$ & $442(89)$ & $521(95)$ & $580(98)$ & $2034(87)$ & $<0.001$ \\
\hline $\begin{array}{l}\text { Birth in hospital with } \\
\text { designated tertiary neonatal } \\
\text { intensive care unit (\% live } \\
\text { births) }\end{array}$ & $69(45)$ & $163(48)$ & $254(58)$ & $343(66)$ & $350(60 \%)$ & $1179(58 \%)$ & $<0.001$ \\
\hline $\begin{array}{l}\text { Active stabilisation withheld (\% } \\
\text { live births) }\end{array}$ & $111 / 152(73)$ & $55 / 338(16)$ & $16 / 441(4)$ & $4 / 520(1)$ & $3 / 574(1)$ & 189/2031 (9) & $<0.001$ \\
\hline Admissions for palliative care & 0 & 1 & 2 & 0 & 0 & 3 & - \\
\hline \multicolumn{8}{|l|}{ Admissions for intensive care } \\
\hline Total (\% live births) & $19(13)$ & $217(64)$ & $381(86)$ & $498(96)$ & $571(98)$ & $1686(83)$ & $<0.001$ \\
\hline $\begin{array}{l}\text { Any antenatal steroid (\% of } \\
\text { admissions) }\end{array}$ & $8(42)$ & $140(65)$ & $326(86)$ & $437(88)$ & $486(86)$ & $1397(83)$ & $<0.001$ \\
\hline $\begin{array}{l}\text { Caesarean section (\% of } \\
\text { admissions) }\end{array}$ & $1(5)$ & $12(6)$ & $55(14)$ & $153(31)$ & $250(44)$ & $471(28)$ & $<0.001$ \\
\hline Median (IQR) birth weight $(\mathrm{g}) \ddagger$ & $540(509-574)$ & $600(548-649)$ & $671(610-730)$ & $779(699-850)$ & $879(787-970)$ & $750(639-870)$ & $<0.001$ \\
\hline $\begin{array}{l}\text { Surfactant given at any time (\% } \\
\text { admissions ) }\end{array}$ & $18 / 19(95)$ & 215/217 (99) & $379 / 381(81)$ & 490/498 (98) & $567 / 571$ (99) & $1669 / 1686(99)$ & 0.66 \\
\hline $\begin{array}{l}\text { Admission temperature }<35^{\circ} \mathrm{C} \\
\text { (\% admissions) }\end{array}$ & $5 / 16(31)$ & 60/206 (29) & $64 / 374(17)$ & $58 / 495(12)$ & $37 / 562(7)$ & 224/1653 (14) & $<0.001$ \\
\hline $\begin{array}{l}\text { Total transferred§ within } 24 \\
\text { hours (\% admissions) }\end{array}$ & $3 / 19(16)$ & $53 / 217(24)$ & $84 / 381(22)$ & $85 / 498(17)$ & $74 / 571(13)$ & 299/1686 (18) & $<0.001$ \\
\hline \multicolumn{8}{|l|}{ Survival to 28 days } \\
\hline Total & 5 & 88 & 226 & 378 & 472 & 1169 & - \\
\hline$\%$ of live births $(95 \% \mathrm{Cl})$ & $3(1$ to 8$)$ & 26 (21 to 31 ) & 51 (46 to 56 ) & 73 (68 to 76$)$ & 81 (78 to 85 ) & 57 (55 to 60$)$ & $<0.001$ \\
\hline$\%$ of admissions $(95 \% \mathrm{Cl})$ & 26 (9 to 51$)$ & 41 (34 to 47 ) & 59 (54 to 64$)$ & 76 (72 to 80$)$ & 83 (79 to 86$)$ & 69 (67 to 72$)$ & $<0.001$ \\
\hline \multicolumn{8}{|l|}{ Survival to discharge } \\
\hline Total & 3 & 66 & 178 & 346 & 448 & 1041 & - \\
\hline
\end{tabular}


Table 1 (continued)

\begin{tabular}{|c|c|c|c|c|c|c|c|}
\hline & \multicolumn{6}{|c|}{ Gestational age (weeks) } & \multirow[b]{2}{*}{ P value* } \\
\hline & 22 & 23 & 24 & 25 & 26 & $22-26$ & \\
\hline$\%$ of live births $(95 \% \mathrm{Cl})$ & $2(0$ to 6$)$ & 19 (15 to 24$)$ & $40(36$ to 45$)$ & $66(62$ to 71$)$ & 77 (73 to 81$)$ & 51 (49 to 53 ) & $<0.001$ \\
\hline$\%$ of admissions $(95 \% \mathrm{Cl})$ & 16 (3 to 40$)$ & 30 (24 to 37$)$ & 47 (41 to 52$)$ & $69(65$ to 74$)$ & 78 (75 to 82$)$ & $62(59$ to 64$)$ & $<0.001$ \\
\hline $\begin{array}{l}\text { Median age (days) at discharge } \\
\text { (IQR) }\end{array}$ & $124(119-252)$ & $134(115-171)$ & $116(98-141)$ & $102(87-1221)$ & $91(80-113)$ & $102(86-113)$ & $<0.001$ \\
\hline
\end{tabular}

IQR=interquartile range.

* $P$ value for association of gestational age using either logistic regression or regression with gestational age in days. †Includes all births by caesarean section when fetus was known to be alive at beginning of procedure.

$\ddagger$ Missing for one baby born at 23 weeks' gestation. Birth weights for subgroups of live births and admissions by multiple birth, sex, and gestational age are given as appendix 2 (live births) and 3 (admissions).

$\S$ Transferred to another hospital for ongoing care within 24 hours of birth. 
Table 2| Major neonatal morbidity among babies born between 22 and 26 weeks' gestation who survived to discharge, England, 2006. Figures are numbers (percentage, $95 \%$ confidence interval)

\begin{tabular}{|c|c|c|c|c|c|c|c|}
\hline & \multicolumn{6}{|c|}{ Gestational age (weeks) } & \multirow[b]{2}{*}{ P value* } \\
\hline & 22 & 23 & 24 & 25 & 26 & $22-26$ & \\
\hline Total survivors & 3 & 66 & 178 & 346 & 448 & 1041 & \\
\hline \multicolumn{8}{|l|}{ Major morbidities } \\
\hline $\begin{array}{l}\text { Bronchpulmonary dysplasia } \\
\text { (supplementary oxygen at } \\
36 \text { weeks postmenstrual } \\
\text { age) }\end{array}$ & $3(100,29$ to 100$)$ & $57(86,76$ to 94$)$ & $142(80,73$ to 85$)$ & $231(67,62$ to 72$)$ & $272(61,56$ to 66$)$ & $705(68,65$ to 71$)$ & $<0.001$ \\
\hline $\begin{array}{l}\text { Severe bronchopulmonary } \\
\text { dysplasia } †\end{array}$ & $2(67,9$ to 99$)$ & $42(64,51$ to 75$)$ & $95(53,46$ to 61$)$ & $136(39,34$ to 45$)$ & $151(34,29$ to 38$)$ & $426(41,38$ to 44$)$ & $<0.001$ \\
\hline $\begin{array}{l}\text { Retinopathy stage } \geq 3 \text { (in at } \\
\text { least one eye) }\end{array}$ & $1(33,1$ to 91$)$ & $28(42,30$ to 55$)$ & $63(36,29$ to 43$)$ & $73(21,17$ to 26$)$ & $48(11,8$ to 14$)$ & $213(21,18$ to 23$)$ & $<0.001$ \\
\hline $\begin{array}{l}\text { Laser treatment for } \\
\text { retinopathy }\end{array}$ & $0(0,0$ to 71$)$ & $22(33,22$ to 46$)$ & $48(27,21$ to 34$)$ & $57(7,13$ to 21$)$ & $39(9,6$ to 12$)$ & $166(16,14$ to 19$)$ & $<0.001$ \\
\hline $\begin{array}{l}\text { Severe abnormality on last } \\
\text { available cerebral } \\
\text { ultrasound scan } \ddagger\end{array}$ & $1(33,1$ to 91$)$ & $4(6,2$ to 15$)$ & $27(15,10$ to 21$)$ & $50(15,11$ to 19$)$ & $53(12,9$ to 15$)$ & $135(13,11$ to 15$)$ & 0.87 \\
\hline $\begin{array}{l}\text { Laparotomy for necrotising } \\
\text { enterocolitis }\end{array}$ & $1(33,1$ to 91$)$ & $4(6,2$ to 15$)$ & $20(11,7$ to 17$)$ & $25(7,5$ to 11$)$ & $29(6,4$ to 9$)$ & $79(8,6$ to 9$)$ & 0.020 \\
\hline \multicolumn{8}{|l|}{ Other morbidities } \\
\hline \multicolumn{8}{|c|}{$z$ score $<-2$ at 40 weeks postmenstrual age: } \\
\hline Weight & $1(33,1$ to 91$)$ & $37(57,44$ to 69$)$ & $90(51,43$ to 58$)$ & $143(43,37$ to 48$)$ & $183(41,37$ to 46$)$ & $454(44,41$ to 48$)$ & $<0.001$ \\
\hline $\begin{array}{l}\text { Occipitofrontal } \\
\text { circumference }\end{array}$ & $0(0$ to 71$)$ & $29(46,33$ to 59$)$ & $62(36,29$ to 44$)$ & $78(25,20$ to 30$)$ & $82(20,16$ to 24$)$ & $251(26,23$ to 29$)$ & $<0.001$ \\
\hline $\begin{array}{l}\text { Treated patent ductus } \\
\text { arteriosus§ }\end{array}$ & $2(67,9$ to 99$)$ & $50(77,65$ to 86$)$ & $118(68,61$ to 75$)$ & $162(49,44$ to 55$)$ & $168(41,36$ to 46$)$ & $500(51,46$ to 54$)$ & $<0.001$ \\
\hline $\begin{array}{l}\text { Patent ductus arteriosus } \\
\text { treated surgically }\end{array}$ & $2(67,9$ to 99$)$ & $24(36,25$ to 49$)$ & $41(23,17$ to 30$)$ & $59(17,13$ to 22$)$ & $40(9,6$ to 12$)$ & $166(16,14$ to 18$)$ & $<0.001$ \\
\hline $\begin{array}{l}\text { Gram negative bacteraemia } \\
>72 \text { hours after birth }\end{array}$ & $0(0,0$ to 71$)$ & $12(18,10$ to 30$)$ & $22(13,8$ to 18$)$ & $19(6,3$ to 9$)$ & $28(6,4$ to 9$)$ & $81(8,6$ to 10$)$ & 0.001 \\
\hline $\begin{array}{l}\text { Coagulase negative } \\
\text { staphylococcal bacteraemia } \\
>72 \text { hours after birth }\end{array}$ & $3(100,29$ to 100$)$ & $37(56,43$ to 68$)$ & $106(61,53$ to 68$)$ & $179(52,47$ to 58$)$ & $189(43,38$ to 48$)$ & $514(50,47$ to 53$)$ & $<0.001$ \\
\hline $\begin{array}{l}\text { Positive fungal blood culture } \\
\text { at any age }\end{array}$ & $0(0,0$ to 71$)$ & $2(3,0$ to 11$)$ & $9(5,2$ to 9$)$ & $17(5,3$ to 8$)$ & $8(2,1$ to 4$)$ & $36(4,2$ to 5$)$ & 0.018 \\
\hline $\begin{array}{l}\text { Survival without major } \\
\text { morbidity }\end{array}$ & $1(33,1$ to 91$)$ & $15(23,13$ to 35$)$ & $52(29,23$ to 37$)$ & $133(38,33$ to 44$)$ & $222(50,45$ to 54$)$ & $423(41,38$ to 44$)$ & $<0.001$ \\
\hline
\end{tabular}

${ }^{*} \mathrm{P}$ value for association of gestational age using either logistic regression or regression with gestational age in decimal weeks.

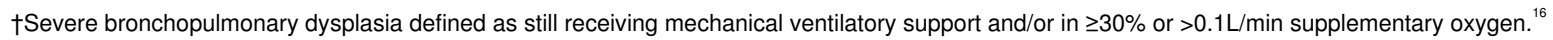

$\ddagger$ Severe abnormality on cerebral ultrasonography defined as scan showing one or more of ventriculomegaly, parenchymal cysts, haemorrhagic parenchymal infarction.

$\S$ Patent ductus arteriosus treated with either indometacin, ibuprofen, or surgical ligation

TMajor morbidity defined as any of: severe abnormality on cerebral ultrasonography, severe bronchopulmonary dysplasia, retinopathy of prematurity stage 3 or more, or laparotomy for necrotising enterocolitis 
Table 3| Population characteristics of admissions to intensive care of babies born between 22 and 25 weeks' gestation in England in EPICure (March to December 1995) and EPICure 2 (January to December 2006) cohorts. Figures are numbers (percentages) unless stated otherwise

\begin{tabular}{|c|c|c|c|}
\hline & $\begin{array}{l}\text { EPICure } \\
(n=666)\end{array}$ & $\begin{array}{c}\text { EPICure } 2 \\
(n=1115)\end{array}$ & $\begin{array}{c}\text { Difference } \\
(95 \mathrm{Cl})\end{array}$ \\
\hline Singletons & $474(71)$ & $821(74)$ & $2.5(-2$ to 7$)$ \\
\hline Male & $357(54)$ & $580(52)$ & $-2(-7$ to 3$)$ \\
\hline Median (IQR) birth weight $(\mathrm{g}) \dagger$ & $695(620-787)$ & $697(610-779)$ & $-2 \mathrm{~g}(-14 \mathrm{~g}$ to $10 \mathrm{~g}) \ddagger$ \\
\hline \multicolumn{4}{|l|}{ Maternal ethnicity: } \\
\hline White & $495(74)$ & $728(65)$ & $-9(-13 \text { to }-5)^{\star \star \star}$ \\
\hline Afro-Caribbean & $103(16)$ & $216(19)$ & $4(0 \text { to } 8)^{\star}$ \\
\hline Indian subcontinent & $45(7)$ & $117(11)$ & $4(1 \text { to } 6)^{* *}$ \\
\hline Other & $12(2)$ & $37(3)$ & 1.5 (0 to 3$)$ \\
\hline Missing & $11(2)$ & $17(2)$ & $0(-1$ to 1$)$ \\
\hline \multicolumn{4}{|l|}{ Obstetric problems: } \\
\hline Pre-eclampsia & $21 / 659(3)$ & $52 / 1110(5)$ & $1.5(0$ to 3$)$ \\
\hline Membranes ruptured $>24$ hours & $160 / 659(24)$ & $306 / 1110(27)$ & $3(-1$ to 7.5$)$ \\
\hline Cervical suture & $59 / 659(9)$ & $81 / 1110(7)$ & $-2(-4$ to 1$)$ \\
\hline Antepartum haemorrhage & $176 / 659(27)$ & $216 / 1112(20)$ & $-7(-11 \text { to }-3)^{\star \star \star}$ \\
\hline Clinical diagnosis of chorioamnionitis & $123 / 659(19)$ & $248 / 1081(23)$ & $4(0 \text { to } 8)^{\star}$ \\
\hline Any antenatal steroid & $448 / 661(68)$ & $911 / 1108(82)$ & $14(10 \text { to } 19)^{\star \star \star}$ \\
\hline Antenatal steroid $>24$ hours before birth & $273 / 661(41)$ & $551 / 1104(50)$ & $9(4 \text { to } 13)^{* \star *}$ \\
\hline Maternal tocolysis & 174/652 (27) & $369 / 1109(33)$ & $7(2 \text { to } 11)^{\star \star}$ \\
\hline Caesarean section & $117 / 665(18)$ & $221 / 1113(20)$ & $2(-1$ to 6$)$ \\
\hline Heart rate $>100$ at $5 \mathrm{~min}$ & $556 / 645(86)$ & 985/1086 (91) & $5(1 \text { to } 8)^{\star \star}$ \\
\hline Admission temp $<35^{\circ} \mathrm{C}$ & $255 / 626(41)$ & 187/1091 (17) & $-24(-28 \text { to }-19)^{\star \star \star *}$ \\
\hline Transfer within 24 hours of birth & $103 / 665(16)$ & $225 / 1115(20)$ & $5(1 \text { to } 8)^{\star}$ \\
\hline Surfactant at any time & $574 / 664(86)$ & $1102 / 1115(99)$ & $12(10 \text { to } 15)^{\star \star \star}$ \\
\hline Median (IQR, range) CRIB I score & $11(8-14,1-22)$ & $9(5-11,1-23)$ & $-2(-3$ to -2$) \ddagger^{\star \star \star}$ \\
\hline
\end{tabular}

IQR=interquartile range.

${ }^{*} \mathrm{P} \leq 0.05,{ }^{* \star} \mathrm{P} \leq 0.01,{ }^{\star * \star} \mathrm{P} \leq 0.001$.

†Missing for one baby from 2006 cohort.

‡Difference in means. 
Table 4| Principal causes of death of babies admitted for intensive care in those born between 22 and 25 weeks' gestation in England in EPICure (March to December 1995) and EPICure 2 (January to December 2006) cohorts. Figures are numbers (percentages)

\begin{tabular}{|c|c|c|c|}
\hline & EPICure $(n=400)$ & EPICure 2 ( $n=522)$ & $\%$ Difference (95\% Cl) \\
\hline Congenital malformation & $6(2)$ & $4(1)$ & $-1(-2$ to 1$)$ \\
\hline Pulmonary insufficiency & $119(30)$ & $85(16)$ & $-13(-19 \text { to }-8)^{\star * *}$ \\
\hline $\begin{array}{l}\text { Respiratory distress syndrome/intracerebral } \\
\text { haemorrhage/infection }\end{array}$ & $125(31)$ & $174(33)$ & 2 (-4 to 8$)$ \\
\hline Late sequelae of ventilation & $37(9)$ & $40(8)$ & $-2(-5$ to 2$)$ \\
\hline Infection & $32(8)$ & $84(16)$ & $8(4 \text { to } 12)^{\star \star \star}$ \\
\hline Intracranial haemorrhage & $17(4)$ & $33(6)$ & $2(-1$ to 5$)$ \\
\hline Necrotising enterocolitis & $12(3)$ & $63(12)$ & $9(6 \text { to } 12)^{\star \star *}$ \\
\hline Othert & $42(11)$ & $35(7)$ & $-4(-8 \text { to } 0)^{*}$ \\
\hline Not known & $10(3)$ & $4(1)$ & $-2(-3 \text { to } 0)^{*}$ \\
\hline
\end{tabular}

${ }^{*} \mathrm{P} \leq 0.05,{ }^{* *} \mathrm{P} \leq 0.01,{ }^{* * *} \mathrm{P} \leq 0.001$.

†In 2006 "other" deaths included pulmonary haemorrhage $(n=18)$, renal failure $(n=5)$, pulmonary hypoplasia ( $n=3)$, air leak and thromboembolism ( $n=2$ of each), and one each of twin to twin transfusion, refractory hypotension, late encephalopathy, and operative complication of ligation of patent ductus arteriosus. 
Table 5 | Predictive multivariable models for inpatient deaths and four major neonatal morbidities in survivors born at 22-25 weeks' gestation in 1995 and 2006. Figures are odds ratios (95\% confidence intervals)

\begin{tabular}{|c|c|c|c|c|c|}
\hline & \multirow{2}{*}{$\begin{array}{l}\text { Death before discharge } \\
\text { for all admissions } \\
\text { ( } n=666 \text { in } 1995 \text { and } 1115 \\
\text { in 2006)* }\end{array}$} & \multicolumn{4}{|c|}{ Survivors ( $n=266$ in 1995 and 593 in 2006) } \\
\hline & & $\begin{array}{l}\text { Severe abnormality† } \\
\text { on cerebral scan } \ddagger\end{array}$ & $\begin{array}{c}\text { Bronchopulmonary } \\
\text { dysplasia (supplementary } \\
\text { oxygen at } 36 \text { weeks PMA) }\end{array}$ & $\begin{array}{l}\text { Supplementary oxygen } \\
\text { at } 40 \text { weeks PMA }\end{array}$ & $\begin{array}{l}\text { Laser treatment for } \\
\text { retinopathy§ }\end{array}$ \\
\hline Total No included & 1630 & 847 & 830 & 821 & 851 \\
\hline $2006 v 1995$ & $1.10(0.85$ to 1.43$)$ & $1.17(0.74$ to 1.85$)$ & $1.04(0.72$ to 1.50$)$ & $1.12(0.81$ to 1.56$)$ & 2.90 (1.71 to 4.92$)$ \\
\hline \multicolumn{6}{|c|}{ Significant clinical associates in combined cohorts: } \\
\hline $\begin{array}{l}\text { Gestational age (per } \\
\text { week) }\end{array}$ & 0.73 (0.62 to 0.86$)$ & - & $0.62(0.45$ to 0.85$)$ & $0.61(-0.47$ to 0.80$)$ & 0.50 (0.37 to 0.67$)$ \\
\hline Birth weight (per SD) & & - & $0.69(0.52$ to 0.91$)$ & $0.73(0.57$ to 0.92$)$ & $0.71(0.53$ to 0.06$)$ \\
\hline Male & $1.60(1.27$ to 2.01$)$ & - & $2.08(1.48$ to 2.91$)$ & $1.76(1.31$ to 2.36$)$ & - \\
\hline Chorioamnionitis & 0.61 (0.46 to 0.82$)$ & - & - & - & - \\
\hline Antenatal steroid $\boldsymbol{\Phi}$ & $0.68(0.53$ to 0.86$)$ & 0.55 (0.37 to 0.82$)$ & - & - & - \\
\hline Tocolysis & - & - & - & $1.51(1.12$ to 2.04$)$ & - \\
\hline Afro-Caribbean ethnicity & - & 0.48 (0.27 to 0.86$)$ & - & - & 0.26 (0.15 to 0.46$)$ \\
\hline Vaginal delivery & $0.58(0.43$ to 0.78$)$ & - & - & - & - \\
\hline Heart rate $>100$ at 5 min & $0.56(0.37$ to 0.84$)$ & - & - & - & - \\
\hline $\begin{array}{l}\text { Admission temperature } \\
\geq 35^{\circ} \mathrm{C}\end{array}$ & $0.75(0.56$ to 1.00$)$ & - & 0.57 (0.33 to 0.98$)$ & $0.64(0.42$ to 0.98$)$ & - \\
\hline \multicolumn{6}{|l|}{ CRIB 1 score $^{\star *}$ (per point): } \\
\hline Combined cohort & - & - & $1.08(1.00$ to 1.15$)$ & $1.07(1.01$ to 1.13$)$ & - \\
\hline 1995 cohort only & $1.32(1.24$ to 1.40$)$ & - & - & - & - \\
\hline 2006 cohort only & $1.22(1.17$ to 1.27$)$ & - & - & - & $1.10(1.02$ to 1.18$)$ \\
\hline
\end{tabular}

$\mathrm{PMA}=$ postmenstrual age.

*Odds ratios additionally adjusted for antepartum haemorrhage in 2006 cohort (OR $0.62,95 \% \mathrm{Cl} 0.43$ to 0.88 ). Interaction of CRIB I with cohort is significant hence values for separate cohorts are given.

†Defined as last available cerebral ultrasound scan with any of ventriculomegaly, parenchymal cysts, haemorrhagic parenchymal infarct.

fOdds ratios additionally adjusted for transfer within 24 hours of birth in 1995 cohort only(OR $3.08,95 \% \mathrm{Cl} 1.36$ to 6.96 ).

§Odds ratios additionally adjusted for antepartum haemorrhage in 1995 cohort only (OR $2.74,95 \% \mathrm{Cl} 1.28$ to 5.88 ).

IAntenatal steroid given to mother $>24$ hours before birth.

${ }^{\star *}$ Clinical risk index for babies (CRIB I), ${ }^{19}$ centred on mean score (9.5) of combined admitted cohorts and to zero in both individual year cohorts. 


\section{Figures}
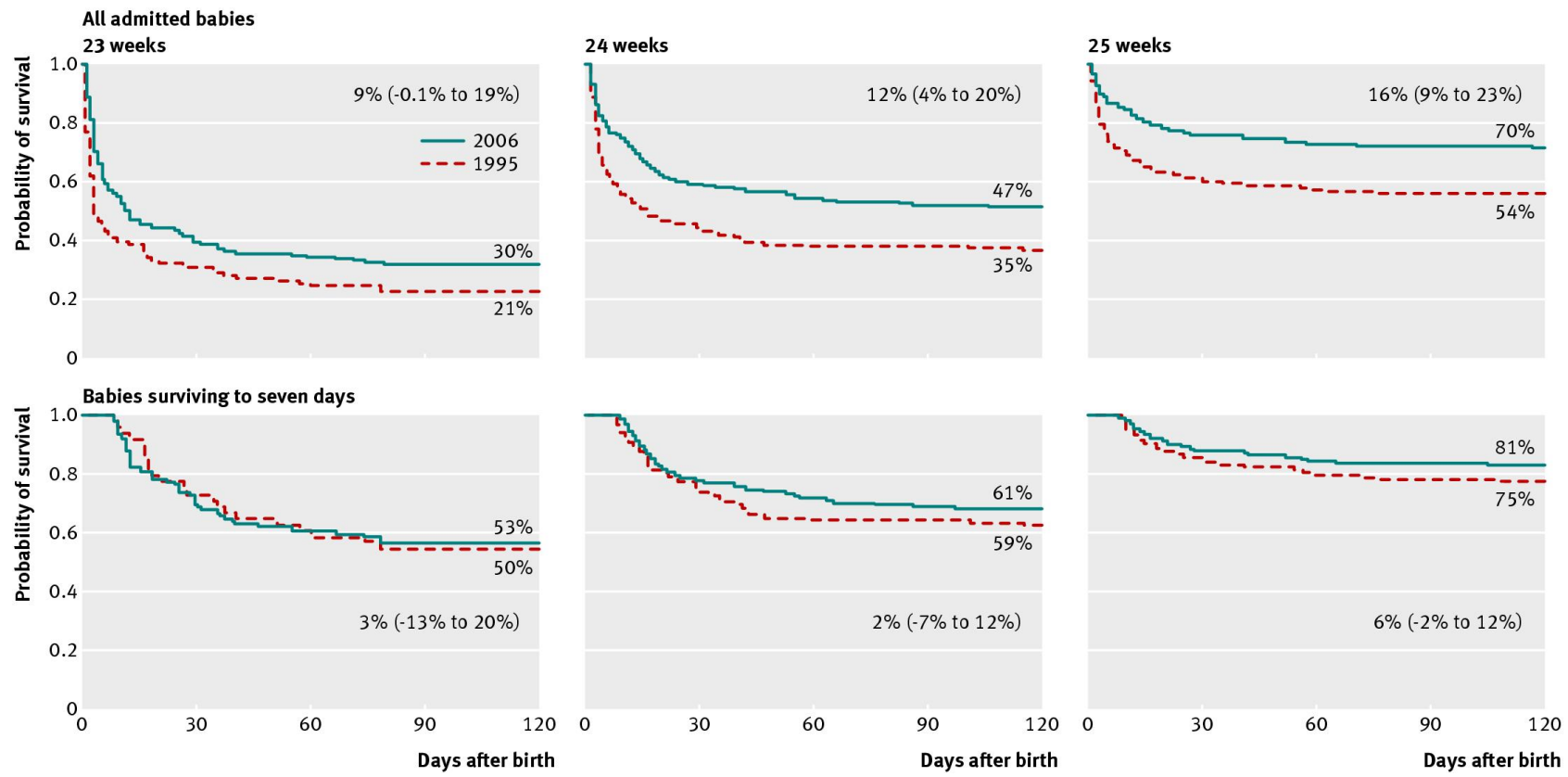

Fig 1 Survival curves by gestational age (23-25 weeks) up to 120 days postnatal age for all babies admitted to neonatal intensive care and those surviving seven days. Each graph shows percentage $(95 \% \mathrm{Cl})$ change in survival to discharge

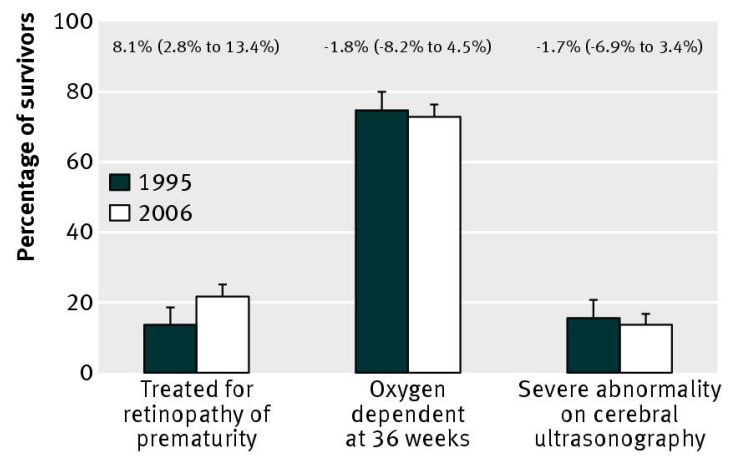

Fig 2 Changes in important neonatal morbidities for babies born at 25 weeks' gestation or less in 1995 and 2006 in England. Figures above bars show \% change (95\% confidence interval) from 1995 to 2006

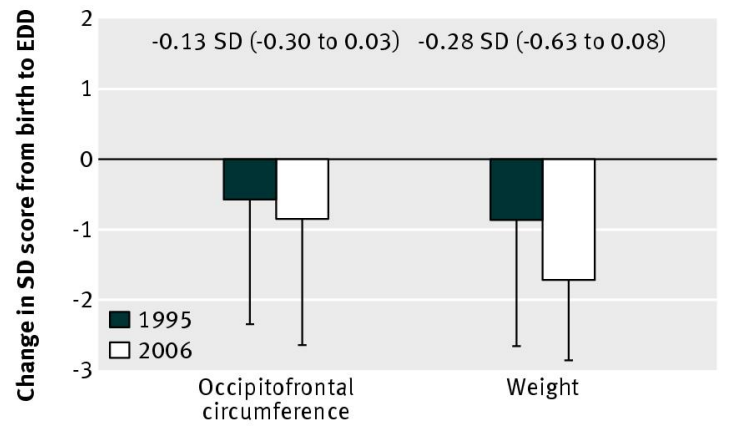

Fig 3 Changes in postnatal occipitofrontal circumference and weight $z$ scores from birth to expected date of delivery (EDD) at discharge from hospital for babies born at 25 weeks of gestation or less in 1995 and 2006 in England. Figures above bars show SD change (95\% confidence interval) from 1995 to 2006 